\title{
Retrograde extension of common carotid artery dissection into the aortic arch
}

\author{
Ichiro Yoshioka, MD, $\mathrm{PhD},{ }^{\mathrm{a}}$ Masahiro Sakurai, $\mathrm{MD}, \mathrm{PhD},{ }^{\mathrm{a}}$ Asako Namai, $\mathrm{MD},{ }^{\mathrm{a}}$ and \\ Shinjitsu Nishimura, MD, $\mathrm{PhD},{ }^{\mathrm{b}}$ Sendai, Japan
}

Internal carotid artery dissection is an important cause of stroke in young patients. A common carotid artery dissection is a relatively rare condition. Most dissections of the internal carotid arteries heal spontaneously with conservative treatment. However, the natural history of the common carotid artery dissection is unknown. We report a case of common carotid artery dissection followed by retrograde extension into aortic arch dissection.

\section{CLINICAL SUMMARY}

A 53-year-old man presented with syncope followed by transient right-sided paresis. He had a history of hypertension but no history of trauma, such as hyperextension or rotation of the neck. Several imaging techniques were performed to determine the cause of the symptoms of transient cerebral ischemia. Diffusion-weighted magnetic resonance imaging did not show acute cerebral infarction. Ultrasonographic analysis demonstrated left carotid artery dissection extending from the common carotid artery to the carotid bulb. A computed tomographic (CT) scan showed that the dissection started from the origin of the common carotid artery, resulting in a double lumen. CT angiographic analysis showed that the external and internal carotid arteries were perfused from the true lumen and the pseudolumen, respectively, and that a re-entry of the dissection was present in the internal carotid artery, where the lumen was reconstituted (Figure 1, $A$ and $B$ ). No evidence of aortic arch involvement was found on CT or magnetic resonance angiographic analysis.

Nonoperative treatment was chosen because of improvement of neurologic symptoms and absence of evidence of hemodynamic insufficiency caused by severe stenosis or occlusion. Anticoagulation or antiplatelet drugs are the current treatment of choice for spontaneous dissection. ${ }^{1,2}$

\footnotetext{
From the Departments of Cardiovascular Surgery ${ }^{\mathrm{a}}$ and Neurosurgery, ${ }^{\mathrm{b}}$ National Hospital Organization, Sendai Medical Center, Sendai, Japan.

Disclosures: Authors have nothing to disclose with regard to commercial support.

Received for publication April 30, 2010; revisions received Aug 5, 2010; accepted for publication Aug 23, 2010; available ahead of print Nov 8, 2010.

Address for reprints: Masahiro Sakurai, MD, PhD, Department of Cardiovascular Surgery, National Hospital Organization, Sendai Medical Center, 2-8-8, Miyagino,

Miyagino-ku, Sendai, 983-8520, Japan (E-mail: sakuraim@snh.go.jp).

J Thorac Cardiovasc Surg 2011;141:e9-10

$0022-5223 / \$ 36.00$

Copyright (C) 2011 by The American Association for Thoracic Surgery

doi:10.1016/j.jtcvs.2010.08.079
}

Anticoagulation therapy was started, but 4 days later, ultrasonographic analysis showed thrombus formation at the true lumen of the dissection, and antiplatelet therapy was added. Three weeks later, complete recanalization in the carotid artery dissection was confirmed by means of ultrasonographic analysis. The patient was discharged, and follow-up CT and ultrasonographic scans were scheduled.

Three months after the carotid artery dissection, the patient presented with severe chest pain. A CT scan showed acute aortic dissection of Stanford type A (Figure 1, C and $D$ ), and an emergency operation was performed with hypothermic circulatory arrest and a technique for open distal anastomosis. Directly inspecting the interior of the aorta, an intimal tear was absent in the ascending aorta, aortic arch, and proximal descending aorta. We speculated that the dissection of the common carotid artery extends retrogradely into the ascending aorta. We performed ascending aortic replacement with a Dacron graft. Postoperative recovery was uneventful, and the patient was discharged on day 30 after the operation. Residual carotid artery dissection continues to be followed up carefully.

\section{DISCUSSION}

Dissection of the extracranial carotid and vertebral arteries is increasingly recognized as a cause of transient ischemic attacks and stroke in young patients. The internal carotid artery is most commonly affected, whereas common carotid artery dissection is a rare condition. In internal carotid artery dissection, healing occurs within 3 to 6 months, with resolution of stenosis in $90 \%$ of cases. ${ }^{1,2}$ However, the natural history of the common carotid artery dissection is unknown. Kanady and colleagues ${ }^{3}$ reported a case of spontaneous isolated innominate artery dissection that healed successfully with nonoperative therapy, which was chosen because the patient's neurologic symptoms were improving at the time of surgical consultation. In contrast, Munakata and associates described a case of acute innominate artery dissection that was treated surgically. ${ }^{4}$ Anterior mediastinal hematoma was observed in CT scans, and replacement of the innominate artery with a Dacron graft was performed on an emergency basis because of the diagnosis of impending rupture of the dissected innominate artery. 

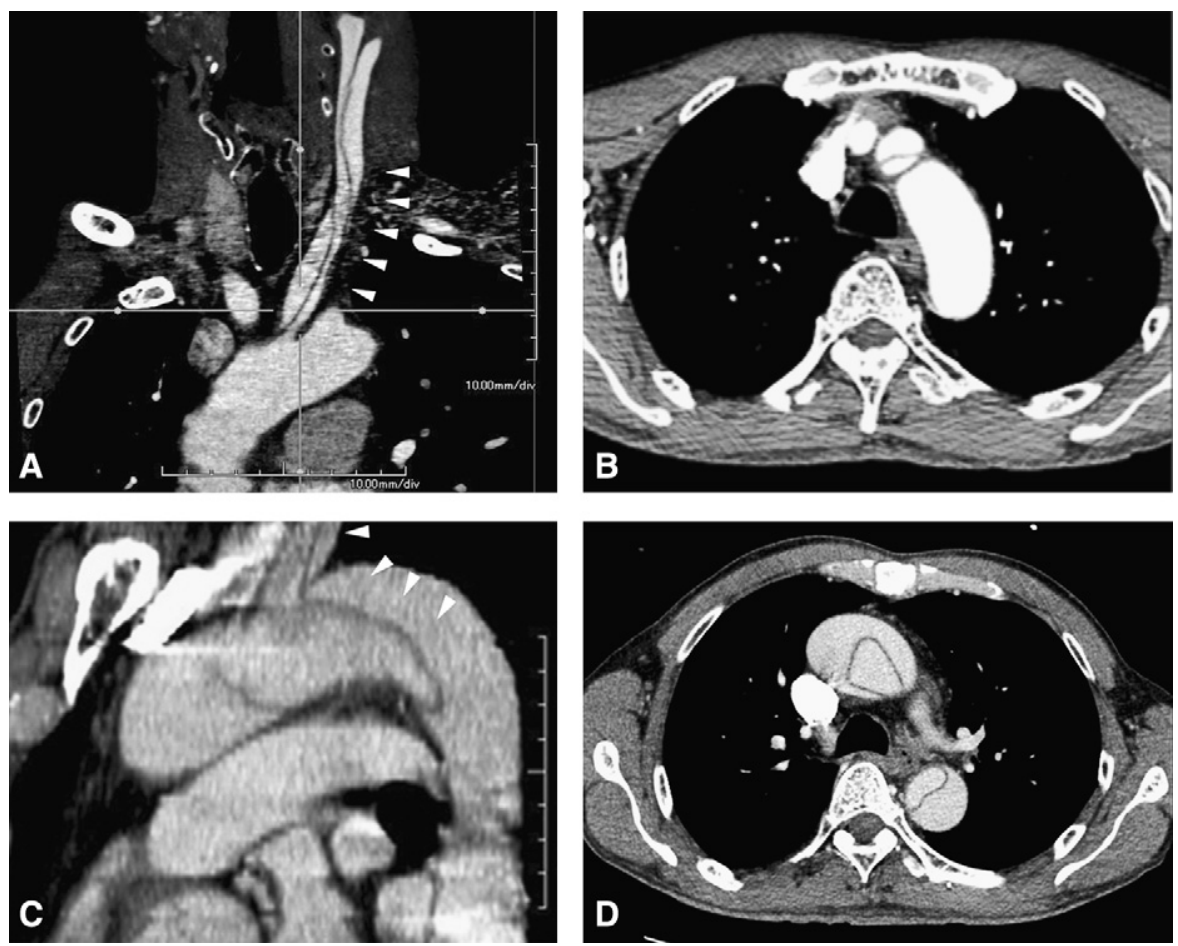

FIGURE 1. A, Computed tomographic (CT) angiogram showing left common carotid artery dissection starting from the origin and extending to the internal carotid artery (arrows). B, CT scan of the chest showing no evidence of aortic arch dissection. C and D, Three months after identification of carotid artery dissection, the dissection had expanded to the aortic arch (arrow).

In our case we elected nonoperative treatment according to the current standard of care for internal carotid artery dissection. If the common carotid artery dissection had the possibility of extending to aortic dissection, surgical replacement of the common carotid artery or aortic arch might be an appropriate therapeutic option. It remains uncertain whether a common carotid artery dissection should be treated as a cervicocephalic dissection or as an arch dissection. However, cases of common carotid artery dissection should be followed for the potential occurrence of stroke caused by thromboembolic or hemodynamic insufficiency because of severe stenosis or occlusion. There has been no previous description of a case that extended to aortic dissection, but our experience suggests that this possibility should also be monitored in follow-up.

\section{References}

1. Redekop GJ. Extracranial carotid and vertebral artery dissection: a review. Can J Neurol Sci. 2008;35:146-52.

2. Schievink WI. Spontaneous dissection of the carotid and vertebral arteries. $N$ Engl J Med. 2001;344:898-906.

3. Kanady K, Hartz R, Massad M, Melen O, Russell E, Feingold R. Spontaneous isolated innominate artery dissection. Neurology. 1990;40:1315-7.

4. Munakata H, Okada K, Tanaka H, Yamashita T, Nakagiri K, Okita Y. Acute dissection of the innominate artery: a case of report. Gen Thorac Cardiovasc Surg. 2008;56:131-3. 